\title{
Elevated Urbanization-driven Plant Accumulation and Human Intake Risks of Polycyclic Aromatic Hydrocarbons in Crops of Peri-urban Farmlands
}

\section{Anping Zhang}

Zhejiang University of Technology

\section{Xintao Ye}

Zhejiang University of Technology

\section{Xindong Yang}

Zhejiang University of Technology

Jiacheng Li

Zhejiang University of Technology

\section{Haofeng Zhu}

Zhejiang University of Technology

\section{Honglei Xu}

Zhejiang University of Technology

Jiaqi Meng

Zhejiang University of Technology

\section{Tianwei Xu}

Zhejiang University of Technology

Jianqiang Sun ( $\nabla$ sunjianqiang@zjut.edu.cn )

Zhejiang University of Technology https://orcid.org/0000-0002-1296-3192

\section{Research Article}

Keywords: Polycyclic aromatic hydrocarbons, Urbanization, Plant uptake, Plant

Posted Date: April 6th, 2021

DOI: https://doi.org/10.21203/rs.3.rs-342282/v1

License: (c) (1) This work is licensed under a Creative Commons Attribution 4.0 International License. Read Full License 
1 Elevated urbanization-driven plant accumulation and human intake

2 risks of polycyclic aromatic hydrocarbons in crops of peri-urban

3 farmlands

4

5 Anping Zhang ${ }^{\dagger}$, Xintao Ye ${ }^{\ddagger}$, Xindong Yang ${ }^{\ddagger}$, Jiacheng $\mathrm{Li}^{\ddagger}$, Haofeng Zhu ${ }^{\ddagger}$, Honglei

$6 \mathrm{Xu}^{\ddagger}$, Jiaqi Meng ${ }^{\ddagger}$, Tianwei Xu $\mathrm{u}^{\ddagger}$, Jianqiang Sun ${ }^{*}, \dagger$

7

$8{ }^{\dagger}$ Key Laboratory of Microbial Technology for Industrial Pollution Control of

9 Zhejiang Province, Zhejiang University of Technology, Hangzhou, 310014, China

$10 \div$ International Joint Research Center for Persistent Toxic Substances, College of

11 Environment, Zhejiang University of Technology, Hangzhou, 310014, China

\section{* Corresponding Author}

E-mail: sunjianqiang@zjut.edu.cn (Jianqiang Sun) 


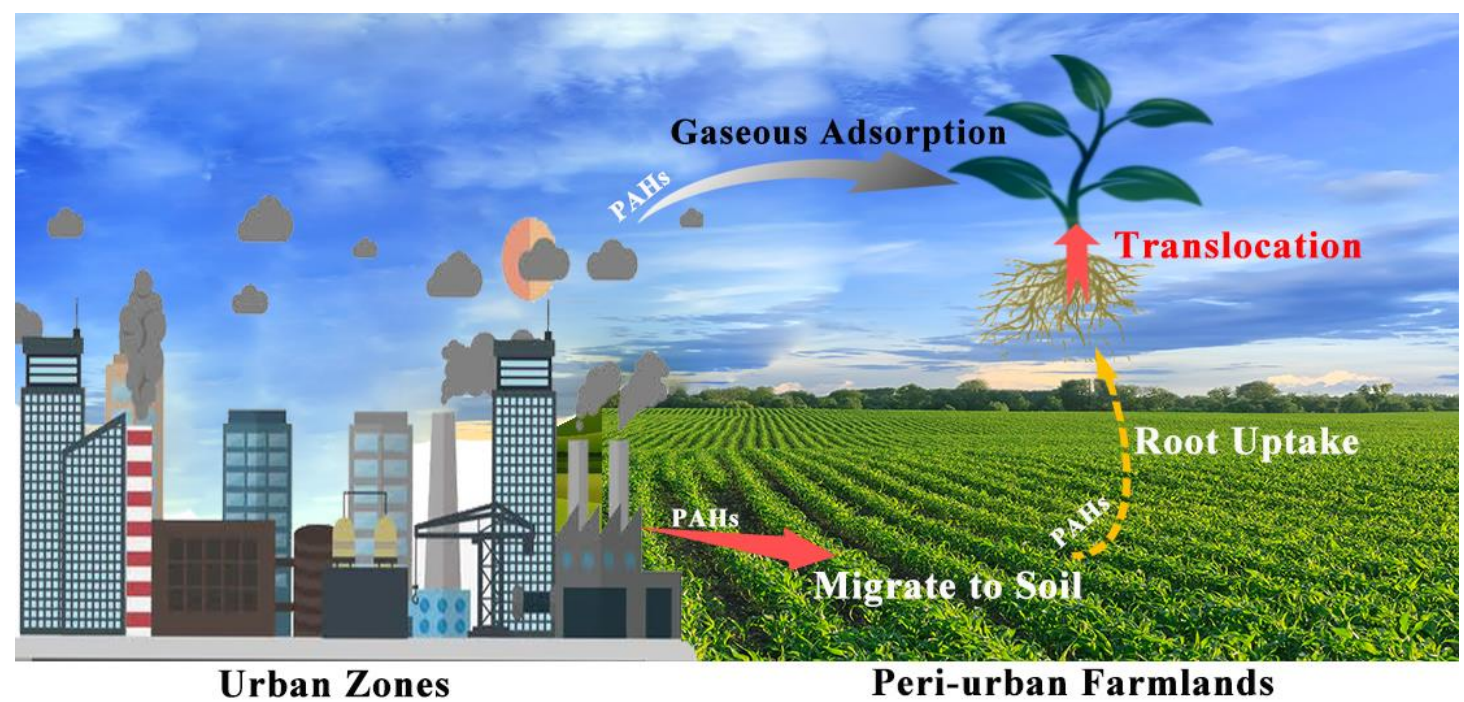




\section{Abstract}

As a ubiquitous carcinogen, polycyclic aromatic hydrocarbons (PAHs) are closely related to anthropogenic activities. The process of urbanization leads to the spatial interlacing of farmlands and urbanized zones. However, field evidence on the influence of urbanization on the accumulation of PAHs in crops of peri-urban farmlands is lacking. This study comparatively investigated the urbanization-driven levels, compositions, and sources of PAHs in 120 paired plant and soil samples collected from the Yangtze River Delta in China and their species-specific human intake risks. The concentrations of PAHs in crops and soils in the peri-urban areas were $2407.92 \mathrm{ng} \mathrm{g}^{-1}$ and $546.64 \mathrm{ng} \mathrm{g}^{-1}$, respectively, which are significantly higher than those in the rural areas. The PAHs in the root were highly relevant to those in the soils $\left(\mathrm{R}^{2}=0.63, \mathrm{p}<0.01\right)$, and the root bioconcentration factors were higher than 1.0 , implying the contributions of root uptake to plant accumulations. However, the translocation factors in the peri-urban areas $(1.57 \pm 0.33)$ were higher than those in the rural areas $(1.19 \pm 0.14)$, indicating the enhanced influence through gaseous absorption. For the congeners, the 2- to 3-ring PAHs showed a higher plant accumulation potential than the 4- to 6-ring PAHs. Principal component and source analyses show that the PAHs in the peri-urban plants predominantly resulted from urbanization parameters, such as coal combustion, vehicle emissions, and biomass burning. The mean values of estimated dietary intake of PAHs from the consumption of peri-urban and rural crops were $9116 \mathrm{ng} \mathrm{d}^{-1}$ and $6601.83 \mathrm{ng} \mathrm{d}^{-1}$, respectively. The intake risks of different crops followed the order rice $>$ cabbage $>$ carrot $>$ pea. Given 
42

43

44

45

46

47

48

49 the significant input of PAHs from urban to farmland, the influence of many anthropogenic pollutants arising from rapid urbanization should be considered when assessing the agricultural food safety.

Keywords: Polycyclic aromatic hydrocarbons; Urbanization; Plant uptake; Plant accumulation; Estimated dietary intake 


\section{Introduction}

With the rapid urbanization and industrialization in many developing countries, many problems, such as land insecurity, worsening of water quality, excessive air pollution, scattered waste disposal, and elevated carbon emissions, are causing environmental degradation (Song et al. 2008). The problem on various anthropogenic organic pollutants, such as polycyclic aromatic hydrocarbons (PAHs), phthalic acid esters, pesticides, polybrominated diphenyl ethers, and polychlorinated biphenyls (PCBs), has been a growing concern (Liu et al. 2014, Sun et al. 2016, Sun et al. 2018). Through the incomplete combustion of organic matter and the use of industrial additives, these pollutants are released, dispersed, and stored in environmental media through the pathways of airborne pollution, reclaimed water irrigation, and waste disposal (Gune et al. 2019, Witter et al. 2014, Wu et al. 2019) and consequently place tremendous direct or indirect pressure on ecosystems around cities (Karageorgou et al. 2020, Li et al. 2016). Extensive agricultural planting areas have been closely adjacent to the expanding cities from the land urbanization process, immediately interlacing urban areas and farmlands (Zhou et al. 2021). As a result of the migrations and accumulations, the risk related to the urban source environmental hazards could be magnified through agricultural production, food chains, and human intake, and ultimately affect human health (Sun et al. 2021, Zhu et al. 2011). Therefore, exploring the interactive relationship between urbanization and the agricultural eco-systems around cities at the level of environmental pollutants has great scientific and practical significance. 
PAH is a typical anthropogenic persistent organic pollutant with lipophilic, environmental persistent, long-distance transmitting, and toxic properties (Lou et al. 2019, White et al. 2016). PAHs are widely present in the natural environment. The U.S. Environmental Protection Agency listed 16 PAHs as priority pollutants, and some of them are even human carcinogens (Wang et al. 2012). They are mainly produced by the incomplete combustion process and pyrolysis of organic matter. Factitious sources include traffic emissions (such as motor vehicle exhaust), industrial waste gas from coal combustion, coal emissions for commercial and household heating, and the combustion of other biomass fuels (especially the burning of straw in rural areas). PAHs are ubiquitously presented in agricultural soils and plant. Given that PAHs pollution mainly occurs in densely populated main urban areas, industrial centers, and main traffic arteries, they can be directly transported through the atmosphere by adsorption through the surface of particles and finally deposited in soils and plants in peri-urban agricultural planting areas. For example, the average concentrations of $\Sigma$ PAHs in amaranth, spinach, leeks, and rice tissue in the Yangtze River Delta of China were 1710.49, 1176.96, 1218.36, and $352.12 \mathrm{ng} \mathrm{g}^{-1} \mathrm{dw}$, respectively (Wang et al. 2017).

As the main source of energy of human beings, several edible crops can absorb and transport PAHs. The primary uptake of PAHs for crops is through absorption by the root part and the aboveground tissue (Houshani et al. 2019, Wild et al. 2005, Zhang and Tao 2009). Subsequently, PAHs are bio-amplified, -enriched, and -accumulated through the food chain, causing harm to human health (Ding et al. 2013, Usman et al. 
2016, Wang et al. 2012). In addition, the risk of human exposure to PAHs is objective, and the incremental lifetime cancer risk (ILCR) could be elevated through the dietary intake of contaminated edible plants. A field study proved that the concentration of PAHs in the soil in urban areas was significantly increased by urbanization (Wang et al. 2020b). Nevertheless, field evidence of the influence of urbanization on the accumulation of PAHs in plants is still lacking.

In this study, the Yangtze River Delta urban agglomeration in China was chosen as the representative area with rapid urbanization, and PAHs were chosen as the model of urbanization-driven pollutants. This study aims to elucidate the relationship between the PAHs in crops in peri-urban farmlands and the urbanization sources by collecting paired plant and soil samples from peri-urban and rural farmlands, analyzing the levels and compositions of 16 PAH congeners in different tissues, and evaluating the sources and the plant uptake and accumulations.

\section{Materials and methods}

\subsection{Chemical reagents and materials}

Standards of PAHs $(>99.0 \%)$, acenaphthene- $\mathrm{d}_{10}(>99.0 \%)$, phenanthrene- $\mathrm{d}_{10}(>$ $99.0 \%)$, chrysene- $\mathrm{d}_{12}(>99.0 \%)$, perylene- $\mathrm{d}_{12}(>99.0 \%)$, and naphthalene- $\mathrm{d}_{8}(>$ 99.0\%) were purchased from Sigma-Aldrich (Shanghai, China). The physical and chemical properties of PAHs are shown in Table S1.

The stock solutions of all the standards were prepared in $n$-hexane and stored in amber glass vials. All the organic solvents used were of HPLC grade (JT Baker, Shanghai, China). Deionized water was prepared using a Milli-Q plus water 
purification system (Millipore Corp, Shanghai, China). Anhydrous sodium sulfate ( $\left.\mathrm{Na}_{2} \mathrm{SO}_{4}\right)$, silica gel (60-100 mesh), florisil (60-100 mesh), and alumina oxide (100-200 mesh) for clean the samples were baked at $400{ }^{\circ} \mathrm{C}$ for $4 \mathrm{~h}$ before use to eliminate potential environmental pollution.

\subsection{Sampling program design}

Soil and plant samples were collected from 60 locations in the Yangtze River Delta in 2019, and 50 of which are adjacent to cities. Ten paired samples were collected from 10 rural areas for comparison with the 50 samples collected from the 50 peri-urban locations. Four kinds of plants were used as samples, namely, carrot (Daucus carota), cabbage (Brassica pekinensis), pea (Pisum sativum), and rice (Oryza sativa). The aboveground and the underground parts of each plant sample were analyzed separately. Sampling site information is provided in Figure S1, and a global positioning system was used to identify the precise location of each site. The samples were collected from farmlands and stored at $-20{ }^{\circ} \mathrm{C}$ until analysis.

\subsection{Chemical treatments of samples}

The sample processing method was slightly improved based on its predecessors (Cao et al. 2017, Sun et al. 2015). The samples were freeze-dried, crushed, and ground through a 100-mesh sieve, and some of the crop samples that were difficult to grind were processed using a tissue grinder. According to Soxhlet extraction, we mixed $10.0 \mathrm{~g}$ of soil samples with diatomaceous earth and copper powder, added 250 $\mathrm{ng} \mathrm{g}^{-1}$ of the substitute standard, and then used $160 \mathrm{~mL}$ of the acetone/n-hexane $(1: 1$, $\mathrm{v} / \mathrm{v}$ ) mixture as the extracting solution for $48 \mathrm{~h}$. Meanwhile, $20 \mathrm{~mL}$ of the 
acetone/n-hexane $(1: 1, \mathrm{v} / \mathrm{v})$ mixture was used for extracting $0.2 \mathrm{~g}$ of crop sample ultrasonically for $20 \mathrm{~min}$, and this procedure was repeated three times. Then, the extract was concentrated and purified through a silica gel column. PAHs were eluted with $40 \mathrm{ml}$ of $\mathrm{n}$-hexane/dichloromethane $(1: 1, \mathrm{v} / \mathrm{v})$, and then the eluate was converted to hexane and concentrated to approximately $1 \mathrm{~mL}$. The internal standard anthracene- $\mathrm{d}_{10}(>99.0 \%)$ was added before GC-MS/MS analysis. GC-MS/MS was used to detect the 16 PAHs (Table S2).

\subsection{Instrumental analysis}

The PAHs were measured using a SIMADAZHU GC-MS/MS-TQ8040 gas-mass spectrometer with an electron impact ion source during multiple reaction monitoring (MRM). The column was an SH-Rxi-5SiLMS $(30 \mathrm{~m} \times 0.25 \mathrm{~mm} \times 0.25 \mu \mathrm{m})$ silica capillary column. In the temperature program, the initial temperature was $60{ }^{\circ} \mathrm{C}$ and maintained for $1 \mathrm{~min}$, increased to $160^{\circ} \mathrm{C}$ at $10{ }^{\circ} \mathrm{C} / \mathrm{min}$ and maintained for $1 \mathrm{~min}$, increased to $180{ }^{\circ} \mathrm{C}$ at $2{ }^{\circ} \mathrm{C} / \mathrm{min}$ and maintained for $1 \mathrm{~min}$, increased to $185^{\circ} \mathrm{C}$ at $0.5^{\circ} \mathrm{C} / \mathrm{min}$ and maintained for $1 \mathrm{~min}$, increased to $190^{\circ} \mathrm{C}$ at $1{ }^{\circ} \mathrm{C} / \mathrm{min}$, and finally increased to $260^{\circ} \mathrm{C}$ at $2{ }^{\circ} \mathrm{C} / \mathrm{min}$ and maintained for $5 \mathrm{~min}$. The carrier gas was high purity helium with a flow rate of $1 \mathrm{~mL} / \mathrm{min}$. The inlet temperature was $250{ }^{\circ} \mathrm{C}$. Table $\mathrm{S} 2$ shows the ion fragments and the retention time. Figure S2 shows the chromatogram of the PAHs.

\subsection{Quality control and quality assurance}

The known concentration of the tracer ( $250 \mathrm{ng}$ ) was mixed into the soil and crops of the blank group experiment, and the recovery rate experiment was carried out. The 
recovery rate ranged from $84 \%$ to $118 \%$, and a blank experiment was performed every 12 samples. The concentration with a signal-to-noise ratio of 3:1 was defined as the limit of detection (LOD), and the LOD of the PAHs was 0.016 (BKFR) -0.72 (ACY) $\mathrm{ng} / \mathrm{g}$.

\subsection{Statistical analysis}

In this study, the PAH ratio and PCA were used to determine the PAH source in soil and crops. The isomer ratios of $\mathrm{BaA} /(\mathrm{BaA}+\mathrm{CHR})$ and $\mathrm{IcdP} /(\mathrm{IcdP}+\mathrm{BghiP})$ can be used to distinguish petroleum combustion from other types of combustion. We performed statistical analysis using the SPSS version 23.0 software and PCA to identify the possible sources of PAHs (Wang et al. 2020a). The input variables were $16 \mathrm{PAH}$ concentrations measured in 60 sets of soil and crop samples, and the three main components were extracted using PCA. We used ArcGIS 10.2 to generate the sampling maps. In addition, Origin was used to deal with the correlation between crops and soil.

\subsection{Risk assessment}

The ILCR model is widely used in soil and vegetables. To assess the degree of human exposure to PAHs through the intake of crops, the following formula is used to estimate the daily intake of the local population ( $\mathrm{Li}$ and Ma 2016, Sun et al. 2019a):

$$
\begin{aligned}
& C S=\sum C \mathrm{i} \times T E F i, \\
& E D I=C S \times I R, \\
& I L C R=\frac{C S F \times E D I \times E F \times E D \times C F}{B W \times A T},
\end{aligned}
$$

where the EDI is the estimated daily intake through the consumption of crops (ng/d), 
and ILCR is the increase in the lifetime cancer risk of an individual. As shown in Table S3, CSF represents the carcinogenic slope factor of ingestion, that is, 7.3 (mg/ $\mathrm{kg} /$ day $)^{-1}$. IR is the intake rate $\left(\mathrm{mg} \mathrm{day}^{-1}\right)$, and the IR values of cabbage, carrot, pea, and rice are $147670,71950,3780$, and 252690, respectively.

EF is the exposure frequency (day/year), ED is the duration of PAH exposure (years), BW is the body weight ( $\mathrm{kg}$ ), AT is the average life span (days), and CS is the sum of the specific PAH concentrations calculated by the toxicity equivalence factor (TEF) method. $\mathrm{Ci}$ is the concentration of each PAH $(\mathrm{mg} / \mathrm{kg})$, and TEFi is the corresponding toxicity equivalent coefficient. $\mathrm{CF}$ is the conversion factor $\left(10^{-6}\right.$ $\mathrm{mg} / \mathrm{ng})$.

\section{Result and discussion}

\subsection{Elevated plant accumulations of PAH}

All the plant samples were divided into aboveground tissue (leaf or fruit) and underground tissue (root). The total concentrations of PAHs in the plants ranged from $984.88 \mathrm{ng} \mathrm{g}^{-1}$ to $3888.46 \mathrm{ng} \mathrm{g}^{-1}$ with an average of $2192.43 \mathrm{ng} \mathrm{g}^{-1}$.

As shown in Fig. 1, the PAHs concentration of the aboveground part was significantly higher than that of the root part $(p<0.01)$. The average concentrations of PAHs in the aboveground and root tissues were 2645.6 and $1846.8 \mathrm{ng} \mathrm{g}^{-1}$, respectively. In both tissues of all the species, the average concentrations of PAHs in the peri-urban locations were higher than those in the rural areas. Among the different kinds of plants, the average concentrations in the entire plants followed the order carrot $>$ cabbage $>$ pea $>$ rice. However, when the edible parts of each species were compared, the order 
changed to cabbage $>$ pea $>$ rice $>$ carrot. The PAHs concentrations in the aboveground tissue among the four species have a large difference, while those in root are relatively close (Fig. 1 and Table 1). The PAHs concentration in the edible parts of leafy vegetables is higher than that in the root-edible plant, which may be affected by two factors, namely, the absorption and transport of soil roots and the absorption of gaseous pollutants by leaves (Li et al. 2020, Zhou et al. 2020). Plant accumulation is affected by its own absorption capacity and metabolic potential and the intensity of exogenous pollution (Sun et al. 2015, Sun et al. 2021). Therefore, the relationship between the aboveground and underground parts must be established, and the soil pollution, the composition, and the source trace must be analyzed further.

\subsection{Concentrations of PAHs in agricultural soil}

The total concentrations of PAHs in the 60 groups of soil samples range from 109.5 $\mathrm{ng} \mathrm{g}^{-1}$ to $2451.89 \mathrm{ng} \mathrm{g}^{-1}$, with an average of $507 \mathrm{ng} \mathrm{g}^{-1}$. The concentrations of PAHs in soil presented in this paper are of medium magnitude and comparable to those in the Yangtze River Delta Urban agglomeration of China (Wang et al. 2017), Shanghai, China (Yang et al. 2020), and Khyber Pakhtunkhwa Province, Pakistan (Waqas et al. 2014) and lower than those determined in Lebanon (Soukarieh et al. 2018) and the Dilovasi in Kocaeli region of Turkey (Cetin 2016).

$$
\text { The total amount of PAHs in the farmlands in the } 50 \text { peri-urban areas was } 547.42
$$
$\mathrm{ng} \mathrm{g}^{-1}$, and that in the 10 suburban areas was $310.57 \mathrm{ng} \mathrm{g}^{-1}$. Both plants and soil are higher in peri-urban than in rural areas. As a city originated pollutant, similar trends were world-widely observed in many countries. For instance, in Lebanon, the BaPeq 
values in industrial and urban soils were 777 and 256 times higher than those in rural soil, respectively (Soukarieh et al. 2018). The concentration of PAHs in the urban areas of the Monterrey Metropolitan Area, Mexico is higher than that in the rural areas (Lopez-Ayala et al. 2019). Therefore, the process of urbanization has a certain impact on the emission of PAHs, which is also the reason why the concentration of PAHs in urban crops is higher than in that in the rural areas.

\subsection{Plant uptake of PAHs from agricultural soil}

Soil and plant are a pair of indispensable components in the agricultural environment. The fate of PAHs in soil-plant systems could be attributed to their transfer process by connecting its levels in soil and plant. Fig. 2 shows that a good correlation exists between the root part concentrations and the soil concentrations $\left(\mathrm{R}^{2}\right.$ $=0.63, p<0.01)$, indicating that PAHs migrate from farmland soil to the roots of plants through root uptake (Tao et al. 2009, Wei et al. 2021, Wild et al. 2005).

However, the correlation between the aboveground part and soil is not high as that between the root part and soil $\left(\mathrm{R}^{2}=0.31, p<0.01\right)$. This phenomenon might be the result of different environmental factors, including traffic source and biomass combustion, which lead to differences in the adsorption process through leafy uptake (Zhang et al. 2019). The absorption of PAHs in the gas phase reportedly accounts for $90.6 \%$ of the total absorption of vegetables, and the absorption of PAHs in soil accounts for $9.4 \%$ of the total absorption of vegetables (Jia et al. 2019). Therefore, the urbanization process has an impact on the pollution of the aboveground tissue. All the bioconcentration factors (BCFs) of the root exceed 1.0, implying the 
contributions of root uptake to the plant accumulations. No significant difference in $\mathrm{BCF}$ value exists between different species. However, the concentrations in the aboveground tissue are higher than those in the root, probably because that the aboveground part is more prone to accumulate PAHs than the root part. The translocation factors (TFs) in the peri-urban areas $(1.57 \pm 0.33)$ are higher than those in the rural area $(1.19 \pm 0.14)$, indicating the enhanced influence through gaseous absorption. In these samples, the aboveground tissue of low-molecular-weight (LMW, $<4$ rings) accounts for $41 \%-93 \%$, with an average of $78 \%$, and the underground tissue of LMW accounts for $55 \%-90 \%$, with an average $73 \%$, indicating that LMW has a greater contribution to the aboveground part than to the underground part. The TFs of the LMW PAHs also exceed 1.0, indicating their easy accumulation in crops, which is consistent with the results of previous studies (Ding et al. 2013, Jia et al. 2018, Wang et al. 2017b, Waqas et al. 2014) (Figs. S3-S6). This phenomenon may be attributed to the high water solubility and vapor pressure of LMW PAHs, which facilitate their absorption by the root and aboveground parts (Li et al. 2020, Zhou et al. 2020). Moreover, LMW PAHs have a low condensation temperature, indicating that their volatility increases and they can exist easily in the gas phase (Kameda 2011). Although LMW PAHs are considered less toxic than other PAHs, they can react with other substances (such as ozone and nitric oxide), and the pollutants formed may be more toxic than the PAHs themselves (Park et al. 2001).

By contrast, high-molecular-weight (HMW, $<4$ rings) PAHs can easily accumulate in the soil compared with LMW PAHs (Huang et al. 2017). This phenomenon may be 
attributed to the disappearance of LMW PAHs through photolysis and volatilization.

This result is consistent with those of previous studies (Marques et al. 2016a, b, Qu et al. 2020). In urban areas with high pollution levels, soil may become the ultimate environmental fate of PAHs through atmospheric deposition (Agarwal et al. 2009, Feng et al. 2017, Zheng et al. 2015). Some studies point out that the HMW PAHs in soil easily enter the human body through sebum (Beriro et al. 2020). Therefore, the HMW PAHs in soil pose a higher risk to human health than the LMW PAHs because of their higher concentrations.

\subsection{Sources related with urbanization}

The PAH isomer ratio has been widely used in environmental media for source identification. In the soil samples, the $\mathrm{BaA} /(\mathrm{BaA}+\mathrm{CHR})$ ratios exceed 0.35 , and the $\mathrm{IcdP} /(\mathrm{IcdP}+\mathrm{BghiP})$ ratios exceed 0.5 , indicating that the combustion of biomass and coal is the main source of PAHs in soil. For the crop samples, the results are consistent with those of the soil samples (Figs.3 and S7), which is consistent with the conclusion of Wang et al. in their study of the Yangtze River Delta (Wang et al. 2017). To explore the composition and sources of PAHs in soil and crops, PCA is used to obtain the component contributions from different sources. The aboveground and root parts of crops and soil have three main components, which account for more than $70 \%$ of the total components (Tables S4-S6). PC1 in soil accounts for $46.782 \%$, of which FRT (0.877), PYR (0.823), BaAN (0.845), CHR (0.876), BbFR (0.886), BkFR (0.792), $\mathrm{BaP}$ (0.935), DahA (0.592), IcdP (0.858), and BghiP (0.835) account for a large proportion, reflecting the emissions from transportation and industry exhaust and the 
combustion of petroleum (Sari et al. 2020). These are some elements related to the city. PC2 accounts for $17.486 \%$, of which ACY (0.828), ACE (0.582), PHE (0.771), and ANT (0.799) account for a large proportion. PC2 indicates the combustion of biomass and coal. PC3 accounts for $9.403 \%$, of which FLR (0.471) and NAP (0.383) account for the most part. PC3 represents the mixture of crude oil emissions and coal combustion (Tables S4-S6) (Qu et al. 2020).

For both the aboveground and underground tissues of crops, PC1, which is dominated by PHE, FRT, PYR, BaAN, CHR, BbFR, BkFR, BaP, DahA, IcdP, and BghiP, reflects the traffic and industrial waste gas emissions and the burning of oil and coal. ACE, FLR, and ANT dominate the second component (PC2), indicating that the combustion of biomass and coal is the main source. NAP and ACY mainly indicate that the third component (PC3) is the emissions from crude oil and the combustion of diesel. Therefore, the PAHs pollution in cities mainly comes from traffic emissions, followed by biomass and petroleum combustion.

\subsection{Health risk assessment}

The ingestion of vegetables and soil contact are major PAH exposure pathways for humans. Thus, we are concerned about crops and soil. In this study, the ILCR and the EDI were calculated based on ingestion to assess the potential risks imposed by the PAHs in soil and crops to human health (Sun et al. 2019b). According to the literature, we conducted a comparative analysis between urban and rural areas, different plants, and adults and children (Wang et al. 2018). Generally, an ILCR lower than $10^{-6}$ is considered safe, an ILCR between $10^{-6}$ and $10^{-4}$ indicates low risk, and an ILCR 
above $10^{-4}$ indicates health problems.

In soil, the ILCR result indicates that almost all samples contaminated with PAHs of below the acceptable risk level, in which are consistent with previous studies (Zhou et al. 2021). The edible part of the vegetable is not the same as the soil, which the ILCR and EDI values are higher in cities than in rural areas. This may be caused by more serious levels of pollution in the city.

Therefore, we further analyze the risk involved in the ingestion of crops from the peri-urban areas. For adults and children, $84 \%$ of the samples have an ILCR risk higher than $10^{-6}$, and the ILCR of the children is slightly higher than that of the adults, indicating that the exposure risk of children is higher than that of adults. Among different crops, peas have the lowest risk, which is less than $10^{-6}$. Those of the other crops exceed $10^{-4}$, which indicate health risks. The intake risks of different crops follows the order rice $>$ cabbage $>$ carrot $>$ pea. Rice has the highest risk because of its relatively high daily intake, followed by cabbage because of its large leaves and high pollutants concentration (Table 2). Rice and cabbage are the most easily accessible crops, so their intake risks deserve attention. Thus, the long-term cumulative risk of the intake of these crops to the human body cannot be ignored.

\section{Conclusion}

This study explored the levels, compositions, and sources of PAHs in soil and crops in the peri-urban farmlands in the Yangtze River Delta urban agglomeration of China and the influence of urbanization on their plant accumulation and human intake risks. The concentrations of PAHs in soil and crops in the peri-urban farmlands are 
generally higher than those in the rural areas, indicating the relatively higher risk of ingestion of those in the agricultural products planted in the peri-urban zones. A significant correlation between the PAHs in the plant roots and the corresponding soil samples was observed, and the calculated root BCF values exceed 1.0, implying the contributions of the root uptake from the urbanization-influenced PAHs in soils to the elevated plant accumulations. However, the correlation between the aboveground part and soil was not as high as that between the root part and soil. Furthermore, the concentrations in the aboveground part were generally higher than those in the root part, with an average TF value of $1.57 \pm 0.33$ in the peri-urban areas, indicating the enhanced influence through the pathway of gaseous absorption of urbansource-PAHs. In addition, the main sources of PAHs in crops are anthropogenic activities, such as traffic emissions and the combustion of coal and oil.

Thus, under the influence of cities, the plant uptake and accumulation of PAHs in peri-urban farmlands could be elevated through two pathways, namely, root uptake from soils contaminated by urban-source-PAHs and direct gaseous uptake through plant leaves. This study has a certain reference significance for alleviating the adverse effects of urbanization and reducing the impact of urban anthropogenic activities on agricultural eco-systems, such as conservation of farmlands in urban planning steps, and planting low-ingestion species of crops. 


\section{Supplementary material}

The supplementary material includes the physicochemical properties of PAHs, the

GC/MS parameters, the parameters used in ILCR, the principal component analysis results, sampling diagrams, chromatograms, the soil and plant concentration distribution and bioconcentration factors, and the PAHs isomerization rate.

\section{Declaration}

\section{Ethics approval and consent to participate}

This study does not report on or involve the use of any animal or human data or tissue.

\section{Consent for publication}

The authors agree to publication in the Journal of Environmental Science and

Pollution Research and also to publication of the article in English by Springer in Springer's corresponding English-language journal.

\section{Availability of data and materials}

The authors declare that (the/all other) data supporting the findings of this study are available within the article (and its supplementary material files).

\section{Competing interests}

All the authors declare no conflict of interest. 


\section{$378 \quad$ Funding}

379 This study was supported by the National Natural Science Foundation of China (2197

$3806160,21577127)$.

382 Authors' contributions

383 Anping Zhang: Conceptualization, Writing - Review \& Editing; Xintao Ye: Writing 384 original draft, Formal analysis; Xindong Yang: Methodology, Software; Jiacheng Li: 385 Methodology; Haofeng Zhu: Investigation; Honglei Xu: Validation; Jiaqi Meng: 386 Visualization; Tianwei Xu: Investigation; Jianqiang Sun: Writing - Review \& Editing, 387 Supervision. 


\section{References}

Agarwal, T., Khillare, P.S., Shridhar, V. and Ray, S. (2009) Pattern, sources and toxic potential of PAHs in the agricultural soils of Delhi, India. J. Hazard. Mater., 163(2-3), 1033-1039.

Beriro, D.J., Cave, M., Kim, A., Craggs, J., Wragg, J., Thomas, R., Taylor, C., Nathanail, C.P. and Vane, C. (2020) Soil-sebum partition coefficients for high molecular weight polycyclic aromatic hydrocarbons (HMW-PAH). J. Hazard., Mater. 398.

Cao, H., Chao, S., Qiao, L., Jiang, Y., Zeng, X. and Fan, X. (2017) Urbanization-related changes in soil PAHs and potential health risks of emission sources in a township in Southern Jiangsu, China. S Sci. Total Environ., 575, 692-700.

Cetin, B. (2016) Investigation of PAHs, PCBs and PCNs in soils around a Heavily Industrialized Area in Kocaeli, Turkey: Concentrations, distributions, sources and toxicological effects. Sci. Total Environ., 560-561, 160-169.

Ding, C., Ni, H.G. and Zeng, H. (2013) Human exposure to parent and halogenated polycyclic aromatic hydrocarbons via food consumption in Shenzhen, China. Sci. Total Environ., 443, 857-863.

Feng, D.L., Liu, Y., Gao, Y., Zhou, J.X., Zheng, L.R., Qiao, G., Ma, L.M., Lin, Z.F. and Grathwohl, P. (2017) Atmospheric bulk deposition of polycyclic aromatic hydrocarbons in Shanghai: Temporal and spatial variation, and global comparison. Environ. Pollut., 230, 639-647. 
Gune, M.M., Ma, W.L., Sampath, S., Li, W.L., Li, Y.F., Udayashankar, H.N., Balakrishna, K. and Zhang, Z.F. (2019) Occurrence of polycyclic aromatic hydrocarbons (PAHs) in air and soil surrounding a coal-fired thermal power plant in the south-west coast of India. Environ. Sci. Pollut. Res. 26(22), 22772-22782.

Houshani, M., Salehi-Lisar, S.Y., Motafakkerazad, R. and Movafeghi, A. (2019) Uptake and distribution of phenanthrene and pyrene in roots and shoots of maize (Zea mays L.). Environ. Sci. Pollut. Res. 26(10), 9938-9944.

Huang, Y.P., Liu, M., Wang, R.Q., Khan, S.K., Gao, D.Z. and Zhang, Y.Z. (2017) Characterization and source apportionment of PAHs from a highly urbanized river sediments based on land use analysis. Chemosphere, 184, 1334-1345.

Jia, J.P., Bi, C.J., Zhang, J.F. and Chen, Z.L. (2019) Atmospheric deposition and vegetable uptake of polycyclic aromatic hydrocarbons (PAHs) based on experimental and computational simulations. Atmos. Environ., 204, 135-141.

Jia, J.P., Bi, C.J., Zhang, J.F., Jin, X.P. and Chen, Z.L. (2018) Characterization of polycyclic aromatic hydrocarbons (PAHs) in vegetables near industrial areas of Shanghai, China: Sources, exposure, and cancer risk. Environ. Pollut., 241, $750-758$.

Kameda, T. (2011) Atmospheric Chemistry of Polycyclic Aromatic Hydrocarbons and Related Compounds. J. Health Sci., 57(6), 504-511.

Karageorgou, K., Manoli, E., Kouras, A. and Samara, C. (2020) Commuter exposure to particle-bound polycyclic aromatic hydrocarbons in Thessaloniki, Greece. Environ. Sci. Pollut. Res. 
Li, G.D., Fang, C.L., Wang, S.J. and Sun, S. (2016) The Effect of Economic Growth, Urbanization, and Industrialization on Fine Particulate Matter (PM2.5) Concentrations in China. Environ. Sci. Technol., 50(21), 11452-11459.

Li, H. and Ma, Y. (2016) Field study on the uptake, accumulation, translocation and risk assessment of PAHs in a soil-wheat system with amendments of sewage sludge. Sci. Total Environ., 560-561, 55-61.

Li, Y., Liu, M., Li, R.K., Sun, P., Xia, H.B. and He, T.H. (2020) Polycyclic aromatic hydrocarbons in the soils of the Yangtze River Delta Urban Agglomeration, China: Influence of land cover types and urbanization. Sci. Total Environ., 715.

Liu, H.H., Hu, Y.J., Luo, P., Bao, L.J., Qiu, J.W., Leung, K.M. and Zeng, E.Y. (2014) Occurrence of halogenated flame retardants in sediment off an urbanized coastal zone: association with urbanization and industrialization. Environ. Sci. Technol., 48(15), 8465-8473.

Lopez-Ayala, O., Gonzalez-Hernandez, L.T., Alcantar-Rosales, V.M., Elizarragaz-de la Rosa, D., Heras-Ramirez, M.E., Silva-Vidaurri, L.G., Alfaro-Barbosa, J.M. and Gaspar-Ramirez, O. (2019) Levels of polycyclic aromatic hydrocarbons associated with particulate matter in a highly urbanized and industrialized region in northeastern Mexico. Atmospheric Pollution Research 10(5), 1655-1662.

Lou, X.Y., Wu, P.R. and Guo, Y. (2019) Urinary metabolites of polycyclic aromatic hydrocarbons in pregnant women and their association with a biomarker of oxidative stress. Environ. Sci. Pollut. Res. 26(26), 27281-27290.

Marques, M., Mari, M., Audi-Miro, C., Sierra, J., Soler, A., Nadal, M. and Domingo, 
J.L. (2016a) Climate change impact on the PAH photodegradation in soils: Characterization and metabolites identification. Environ. Int., 89-90, 155-165.

Marques, M., Mari, M., Audi-Miro, C., Sierra, J., Soler, A., Nadal, M. and Domingo, J.L. (2016b) Photodegradation of polycyclic aromatic hydrocarbons in soils under a climate change base scenario. Chemosphere, 148, 495-503.

Park, J.S., Wade, T.L. and Sweet, S. (2001) Atmospheric distribution of polycyclic aromatic hydrocarbons and deposition to Galveston Bay, Texas, USA. Atmos. Environ., 35(19), 3241-3249.

Qu, Y., Gong, Y., Ma, J., Wei, H., Liu, Q., Liu, L., Wu, H., Yang, S. and Chen, Y. (2020) Potential sources, influencing factors, and health risks of polycyclic aromatic hydrocarbons (PAHs) in the surface soil of urban parks in Beijing, China. Environ. Pollut., 260, 114016.

Sari, M.F., Esen, F. and Tasdemir, Y. (2020) Characterization, source apportionment, air/plant partitioning and cancer risk assessment of atmospheric PAHs measured with tree components and passive air sampler. Environ. Res., 110508.

Song, J.H., Webb, A., Parmenter, B., Allen, D.T. and McDonald-Buller, E. (2008) The impacts of urbanization on emissions and air quality: Comparison of four visions of Austin, Texas. Environ. Sci. Technol., 42(19), 7294-7300.

Soukarieh, B., El Hawari, K., El Husseini, M., Budzinski, H. and Jaber, F. (2018) Impact of Lebanese practices in industry, agriculture and urbanization on soil toxicity. Evaluation of the Polycyclic Aromatic Hydrocarbons (PAHs) levels in soil. Chemosphere, 210, 85-92. 
Sun, J., Wang, Q., Zhuang, S. and Zhang, A. (2016) Occurrence of polybrominated diphenyl ethers in indoor air and dust in Hangzhou, China: Level, role of electric appliances, and human exposure. Environ. Pollut., 218, 942-949.

Sun, J., Wu, X. and Gan, J. (2015) Uptake and Metabolism of Phthalate Esters by Edible Plants. Environ. Sci. Technol., 49(14), 8471-8478.

Sun, J., Wu, Y., Jiang, P., Zheng, L., Zhang, A. and Qi, H. (2019a) Concentration, uptake and human dietary intake of novel brominated flame retardants in greenhouse and conventional vegetables. Environ. Int., 123, 436-443.

Sun, J., Wu, Y., Tao, N., Lv, L., Yu, X., Zhang, A. and Qi, H. (2019b) Dechlorane plus in greenhouse and conventional vegetables: Uptake, translocation, dissipation and human dietary exposure. Environ. Pollut., 244, 667-674.

Sun, J., Xu, Y., Zhou, H., Zhang, A. and Qi, H. (2018) Levels, occurrence and human exposure to novel brominated flame retardants (NBFRs) and Dechlorane Plus (DP) in dust from different indoor environments in Hangzhou, China. Sci. Total Environ., 631-632, 1212-1220.

Sun, J., Yang, X., Shen, H., Xu, Y., Zhang, A. and Gan, J. (2021) Uptake and metabolism of nonylphenol in plants: Isomer selectivity involved with direct conjugation. Environ. Pollut. 270., 116064.

Tao, Y.Q., Zhang, S.Z., Zhu, Y.G. and Christie, P. (2009) Uptake and Acropetal Translocation of Polycyclic Aromatic Hydrocarbons by Wheat (Triticum aestivum L.) Grown in Field-Contaminated Soil. Environ. Sci. Technol., 43(10), 3556-3560. Usman, M., Hanna, K. and Haderlein, S. (2016) Fenton oxidation to remediate PAHs 
in contaminated soils: A critical review of major limitations and counter-strategies. Sci. Total Environ., 569, 179-190.

Wang, C.H., Zhou, S.L., Song, J. and Wu, S.H. (2018) Human health risks of polycyclic aromatic hydrocarbons in the urban soils of Nanjing, China. Sci. Total

Wang, J., Zhang, X.F., Ling, W.T., Liu, R., Liu, J., Kang, F.X. and Gao, Y.Z. (2017) sediments of European Baltic and North Seas, Chinese Bohai and Yellow Seas. Sci. Total Environ., 737.

Wang, Y., Bao, M.J., Zhang, Y.W., Tan, F., Zhao, H.X., Zhang, Q.N. and Li, Q.L. (2020b) Polycyclic aromatic hydrocarbons in the atmosphere and soils of Dalian, China: Source, urban-rural gradient, and air-soil exchange. Chemosphere, 244.

Wang, Y., Tian, Z., Zhu, H., Cheng, Z., Kang, M., Luo, C., Li, J. and Zhang, G. (2012) Polycyclic aromatic hydrocarbons (PAHs) in soils and vegetation near an e-waste recycling site in South China: concentration, distribution, source, and risk assessment. Sci. Total Environ., 439, 187-193.

Waqas, M., Khan, S., Chao, C., Shamshad, I., Qamar, Z. and Khan, K. (2014) Quantification of PAHs and health risk via ingestion of vegetable in Khyber Pakhtunkhwa Province, Pakistan. Sci. Total Environ., 497, 448-458. 
Wei, B.K., Liu, C., Bao, J.S., Wang, Y., Hu, J.C., Qi, M., Jin, J. and Wei, Y.J. (2021) Uptake and distributions of polycyclic aromatic hydrocarbons in cultivated plants around an E-waste disposal site in Southern China. Environ. Sci. Pollut. Res. 28(3), 2696-2706.

White, A.J., Bradshaw, P.T., Herring, A.H., Teitelbaum, S.L., Beyea, J., Stellman, S.D., Steck, S.E., Mordukhovich, I., Eng, S.M., Engel, L.S., Conway, K., Hatch, M., Neugut, A.I., Santella, R.M. and Gammon, M.D. (2016). Environ. Int., 89-90, 185-192.

Wild, E., Dent, J., Thomas, G.O. and Jones, K.C. (2005) Direct observation of organic contaminant uptake, storage, and metabolism within plant roots. Environ. Sci. Technol., 39(10), 3695-3702.

Witter, A.E., Nguyen, M.H., Baidar, S. and Sak, P.B. (2014) Coal-tar-based sealcoated pavement: A major PAH source to urban stream sediments. Environ. Pollut., 185, 59-68.

Wu, Y., Sun, J., Zheng, C., Zhang, X., Zhang, A. and Qi, H. (2019) Phthalate pollution driven by the industrial plastics market: a case study of the plastic market in Yuyao City, China. Environ. Sci. Pollut. Res. Int., 26(11), 11224-11233.

Yang, J., Sun, P., Zhang, X., Wei, X.Y., Huang, Y.P., Du, W.N., Qadeer, A., Liu, M. and Huang, Y. (2020) Source apportionment of PAHs in roadside agricultural soils of a megacity using positive matrix factorization receptor model and compound-specific carbon isotope analysis. J. Hazard. Mater., 403, 123592.

Zhang, J., Li, R., Zhang, X., Bai, Y., Cao, P. and Hua, P. (2019) Vehicular contribution 
of PAHs in size dependent road dust: A source apportionment by PCA-MLR, PMF, and Unmix receptor models. Sci. Total Environ., 649, 1314-1322.

Zhang, Y.X. and Tao, S. (2009) Global atmospheric emission inventory of polycyclic aromatic hydrocarbons (PAHs) for 2004. Atmos. Environ., 43(4), 812-819. Jones, K.C. and Zhang, G. (2015) Elevated Mobility of Persistent Organic Pollutants in the Soil of a Tropical Rainforest. Environ. Sci. Technol., 49(7), 4302-4309.

Zhou, B.-B., Aggarwal, R., Wu, J. and Lv, L. (2021) Urbanization-associated farmland loss: A macro-micro comparative study in China. Land Use Policy, 101, 105228. and harnessing the health effects of rapid urbanization in China. Environ. Sci. Technol., 45(12), 5099-5104. 
Table 1 Concentration of PAHs in different crops

\begin{tabular}{|c|c|c|c|c|c|c|c|c|c|c|}
\hline Plant tissue & Species & Mean & Median & Min & $\operatorname{Max}$ & Mean & Median & Min & $\operatorname{Max}$ & $\begin{array}{c}\text { PAHs (ng/g) } \\
\text { Mean }\end{array}$ \\
\hline & Cabbage & 2189 & 1980.71 & 906.95 & 4288.90 & 551.50 & 531.97 & 159.78 & 1163.85 & 2741.49 \\
\hline \multirow[t]{2}{*}{ part } & Pea & 1779.72 & 1890.66 & 1230.55 & 2178.17 & 643.72 & 504.05 & 390.45 & 1221.95 & 2423.44 \\
\hline & Rice & 1640.79 & 1533.90 & 821.54 & 2930.87 & 474.22 & 452.39 & 117.52 & 691.29 & 2116.77 \\
\hline Underground & Carrot & 1489.44 & 1411.66 & 744.47 & 2301.33 & 494.99 & 392.40 & 92.62 & 1295.73 & 2048.94 \\
\hline \multirow[t]{2}{*}{ part } & Pea & 1150.30 & 1079.22 & 860.94 & 1579.85 & 483.94 & 507.13 & 292.62 & 719.12 & 1635.79 \\
\hline & Rice & 1285.37 & 1232.65 & 672.78 & 1750.01 & 498.92 & 460.39 & 219.46 & 1156.83 & 1784.32 \\
\hline
\end{tabular}


Table 2 Human ingestion risk of PAH of edible parts

\begin{tabular}{cccc} 
& \multicolumn{2}{c}{ ILCR } & \\
\cline { 2 - 3 } & Adults & EDI (ng/d) \\
\hline Peri-urban & $2.06712 \mathrm{E}-04$ & $3.23468 \mathrm{E}-04$ & \\
Rural & $1.49701 \mathrm{E}-04$ & $2.35779 \mathrm{E}-04$ & 6116.00 \\
Cabbage & $1.98775 \mathrm{E}-04$ & $3.09679 \mathrm{E}-04$ & 8761.83 \\
Carrot & $1.34855 \mathrm{E}-04$ & $2.12397 \mathrm{E}-04$ & 5947.12 \\
Pea & $1.41559 \mathrm{E}-05$ & $2.22956 \mathrm{E}-05$ & 624.28 \\
Rice & $3.44266 \mathrm{E}-04$ & $5.4222 \mathrm{E}-04$ & 15182.15 \\
\hline
\end{tabular}




\section{Figure Captions}

Fig. 1. Concentrations of PAHs in different crops collected from peri-urban and rural areas.

Fig. 2. Correlation analysis between soil and crops of aboveground (a) and underground (b).

Fig. 3. Isomer ratio of PAHs of aboveground part (a) and underground part (b) in crops in peri-urban areas. 


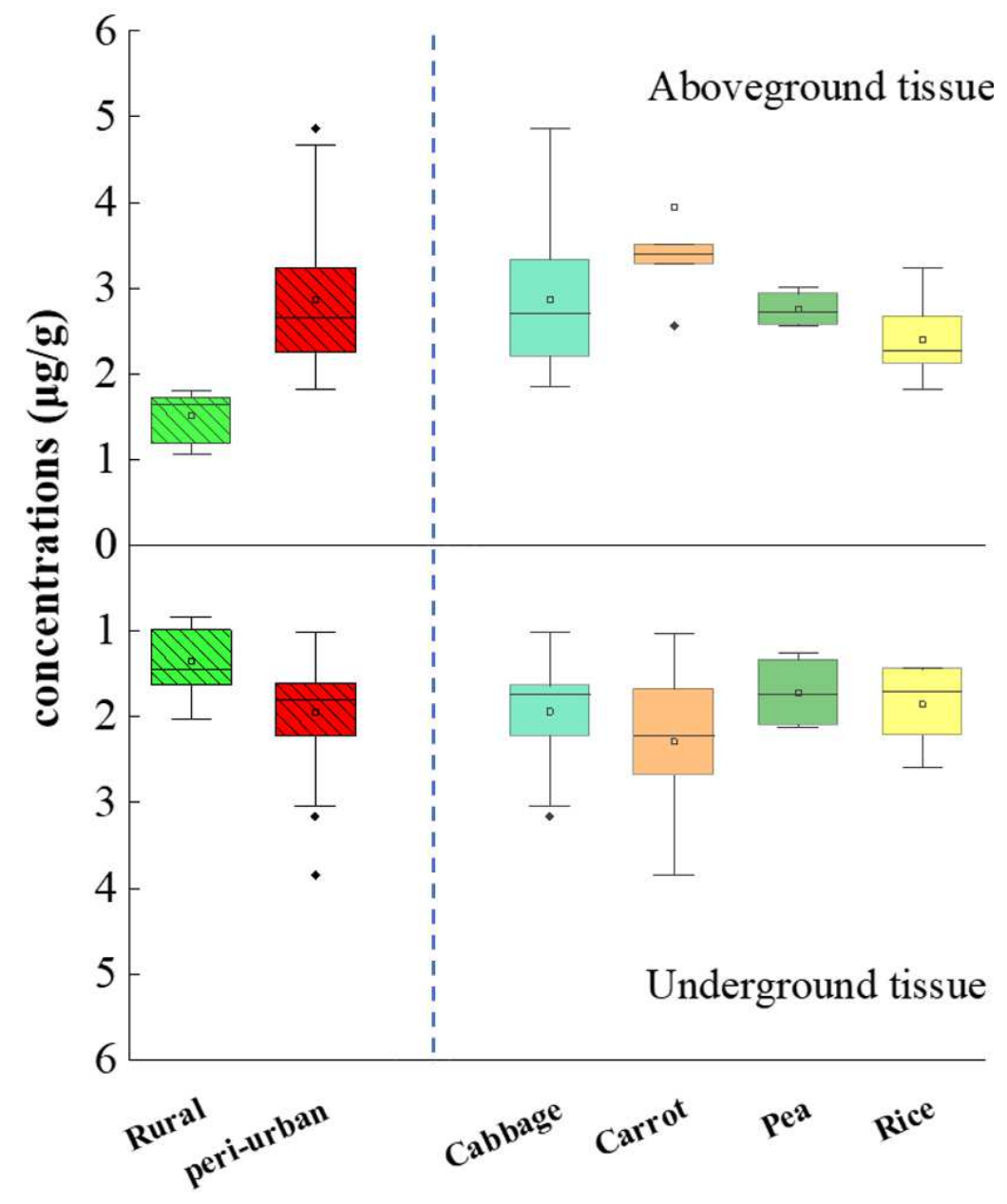

Fig. 1 

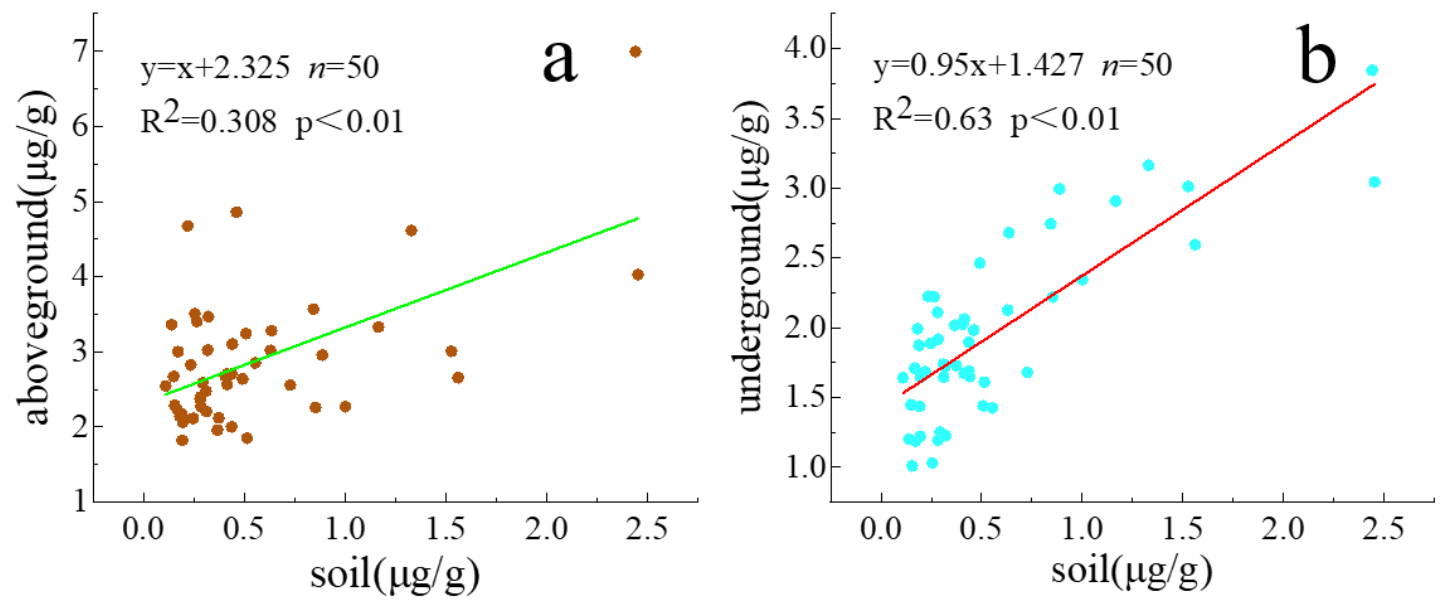

Fig. 2 


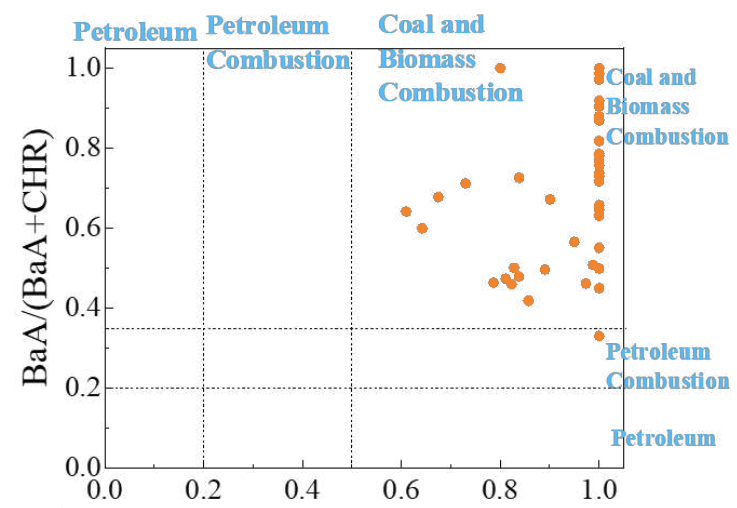

a

$\mathrm{ICdP} /($ BghiP $+\mathrm{ICdP})$

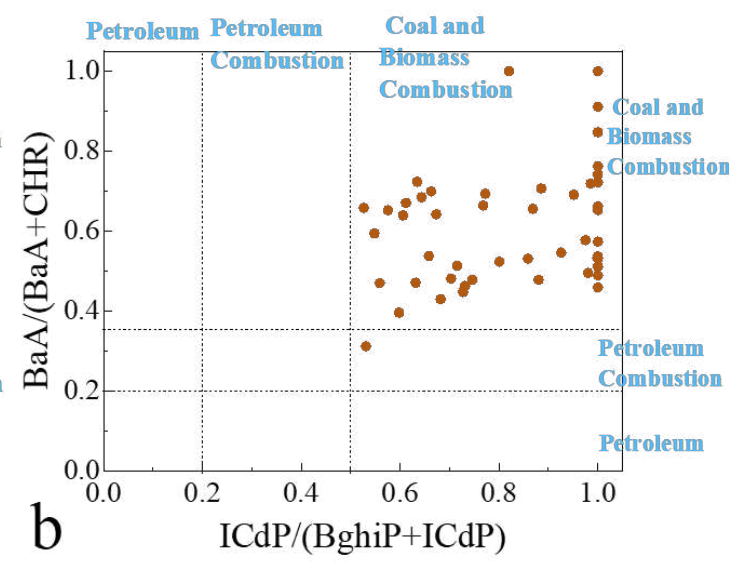

Fig. 3 
Figures

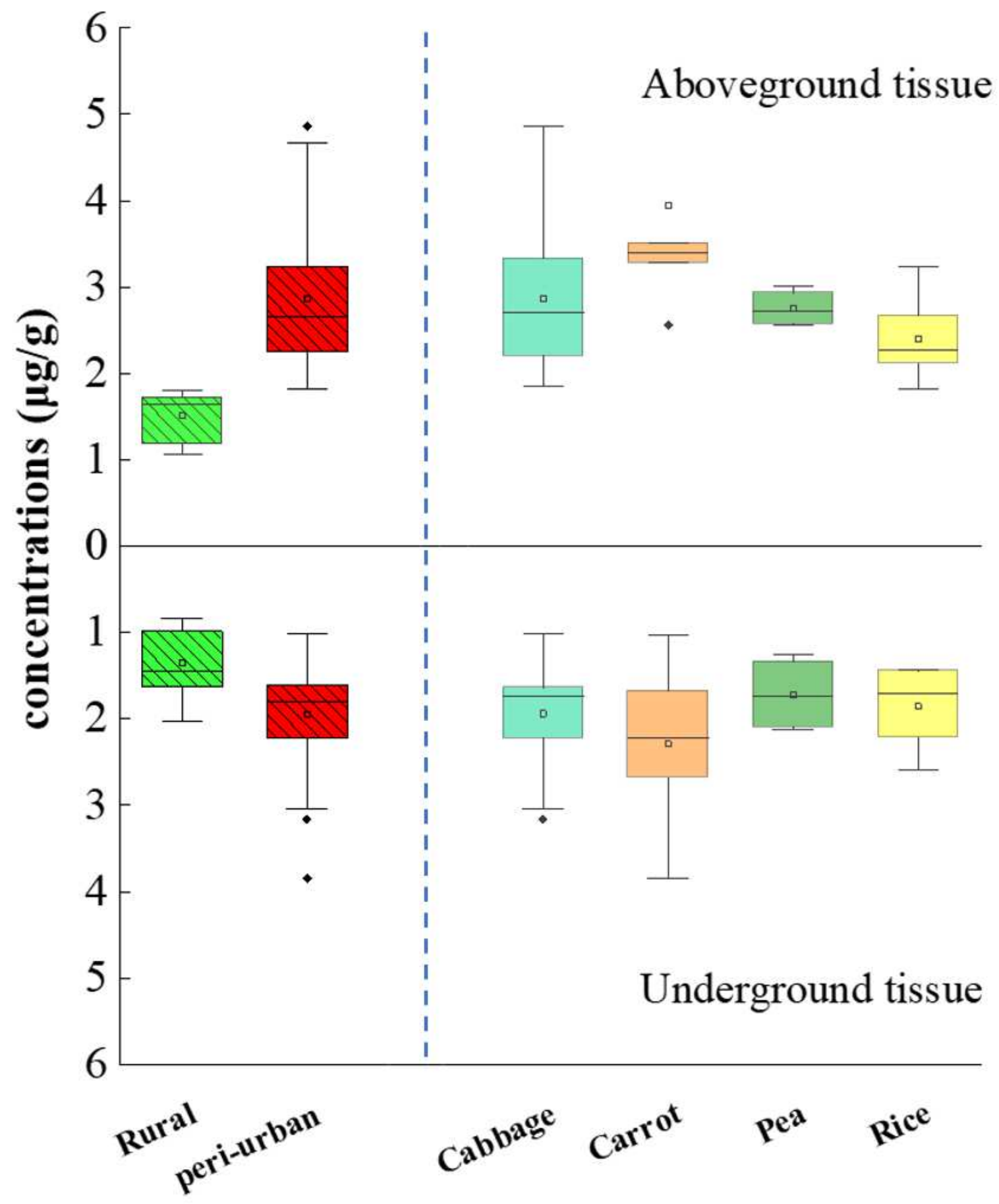

Figure 1

Concentrations of PAHs in different crops collected from peri-urban and rural areas. 

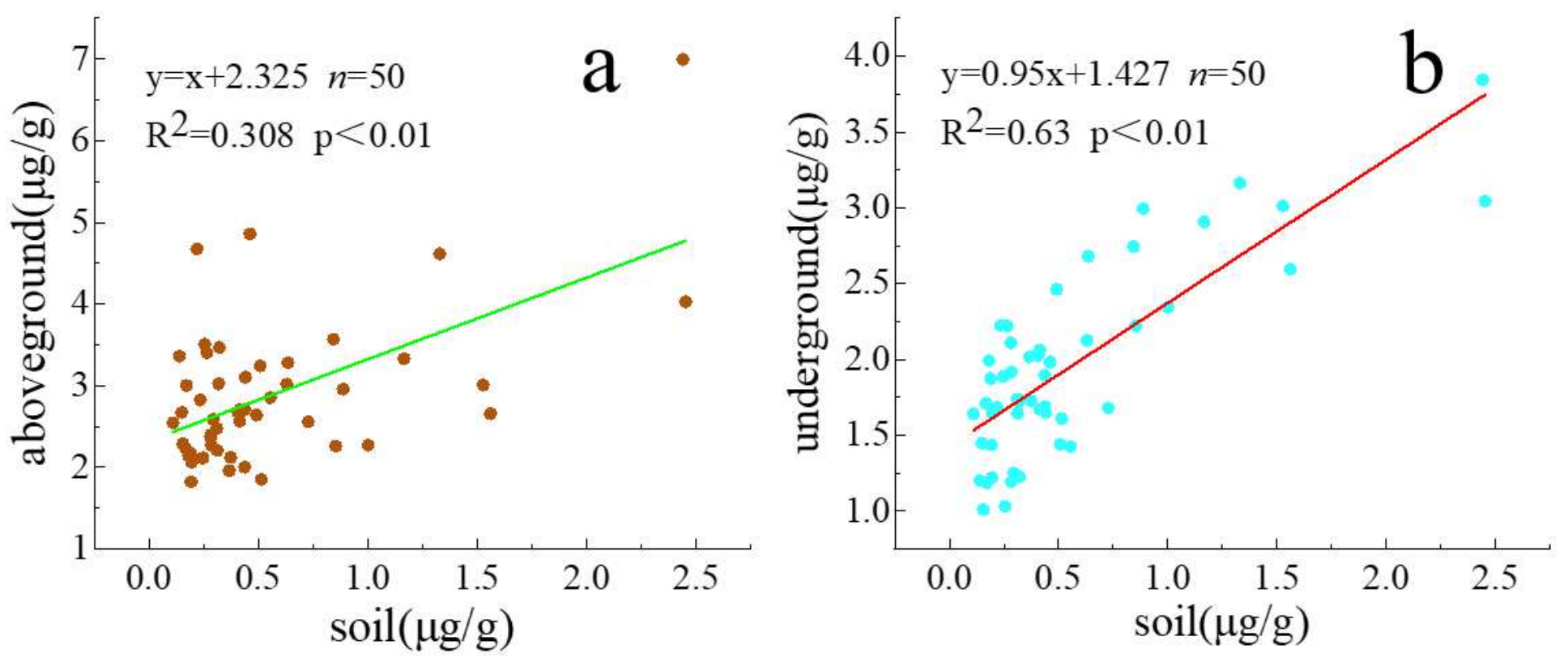

Figure 2

Correlation analysis between soil and crops of aboveground (a) and underground (b).
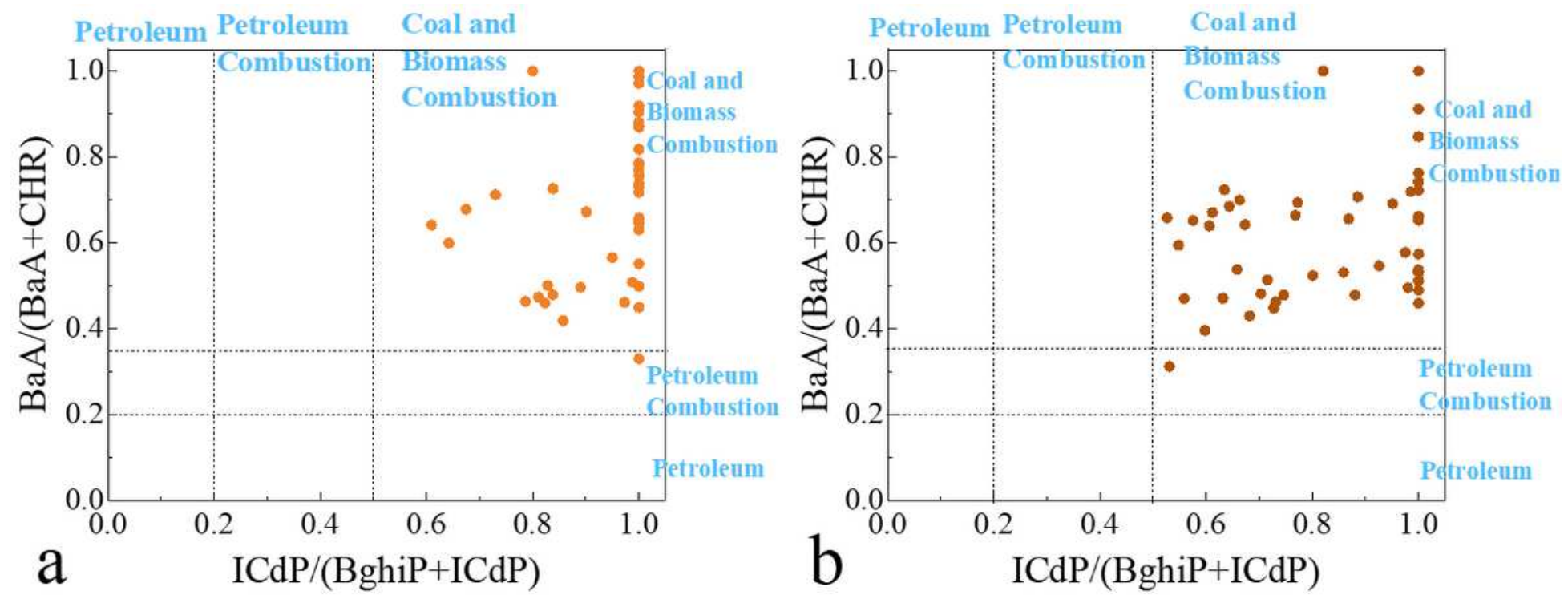

\section{Figure 3}

Isomer ratio of PAHs of aboveground part (a) and underground part (b) in crops in peri-urban areas.

\section{Supplementary Files}

This is a list of supplementary files associated with this preprint. Click to download.

- GraphicalAbstarct.jpeg

- SupplementaryMaterial.doc 